\title{
Extractable phenolic and flavonoid content from selected natural and industry processed spices
}

\author{
Edna Dzifa Doe ${ }^{1,}$, , Adolf Kofi Awua ${ }^{1}$, Seyram Elom Achoribo², Sandra Agbenyegah² \\ ${ }^{1}$ Cellular and Clinical Research Centre-RAMSRI Ghana Atomic Energy Commission, Legon-Accra-Ghana \\ ${ }^{2}$ Applied Radiation Biology Centre-RAMSRI Ghana Atomic Energy Commission, Legon-Accra-Ghana
}

\section{Email address:}

dzidey@yahoo.com(E. D. Doe), a_awua@yahoo.com(A. K. Awua), achoribo@yahoo.fr(S. E. Achoribo), sanbroz88@yahoo.com (S. Agbenyegah)

\section{To cite this article:}

Edna Dzifa Doe, Adolf Kofi Awua, Seyram Elom Achoribo, Sandra Agbenyegah. Extractable Phenolic and Flavonoid Content from Selected Natural and Industry Processed Spices. American Journal of Applied Chemistry. Vol. 1, No. 4, 2013, pp. 53-58. doi: 10.11648/j.ajac.20130104.12

\begin{abstract}
A total number of 22 different spices (both natural spices and industry produced spices) bought from the Accra Markets, Ghana, were analyzed for phenolic and flavonoid content to see their impact in food preparation. The phenolic concentrations were high in the natural spices compared to the industry produced spices with the exception of IPS1 and IPS2. The trend observed is as follows: NS3 $>$ NS5 $>$ NS4 $>$ IPS2 $>$ IPS1 $>$ NS7 $>$ NS6, and NS5 $>$ NS3 $>$ NS7 $>$ NS2 $>$ NS6 $>$ NS4 $>$ IPS1 $>$ IPS2 for $30^{\circ} \mathrm{C}$ and cold extraction respectively. The trend observed for flavonoids in the cold extract was NS3 $>$ NS6 $>$ NS5 $>$ NS2 $>$ NS4 $>$ IPS2 $>$ IPS1 $>$ IPS13 $>$ LS7, while that of the $30^{\circ} \mathrm{C}$ extract was NS3 $>$ NS5 $>$ NS4 $>$ IPS1 $>$ NS7 $>$ IPS2 $>$ IPS3 $>$ NS6 $>$ IPS. Generally, natural spices will potentially contribute extremely more phenolic and flavonoid than industry produced spices if about the same amounts are used in preparing food.
\end{abstract}

Keywords: Phenolic, Flavonoid, Concentrations, Spices

\section{Introduction}

Spices consist of a collection of leaves and/or branches, ripened fruits, seeds, root or bulbs of certain plants; they are usually dried and used to season foods because of their distinctive flavours and aromas [1]. These are flavour and taste enhancers that are used sparingly but frequently in most Africa and some Asian meals. They contain phytochemicals that make them beneficial to human health. Some of the phytochemicals are inhibitory to some food borne microorganisms (antimicrobial activity) and others also act as antioxidant, thereby able to reduce the risk of food poisoning [2]. Spices are also known to possess a wide range of medicinal values [2, 3, 4,]. Because of their characteristic pleasant flavour and aroma, attention has not been paid to the possible presence of toxicants in spices widely used in foods. However, pre-treatments (prior to processing procedures) such as drying, pulverizing and packaging may affect their nutritional values and even introduce contaminants. Flavonoids and other phenolic compounds present in spices possess bioactive properties; protecting cellular systems against oxidative damage. Although spices have been widely used over centuries according to the culture in Ghana, research on their safety, the amount to be used and how often they should be used are scanty. In addition, there is paucity of publication on the phytochemical content of spices though research indicates that they are potentially a repository of phytochemicals which are beneficial to health [2, 5, and 6].

This study therefore sought to ascertain the extent of the difference in the extractable amounts of phenolic and flavonoid content of selected spices and seasoning commonly used in Accra. Also, the study sought to determine difference, if any, in temperature between cold and warm aqueous extraction of these phytochemical in extractable amounts.

\section{Materials and Method}

\subsection{Samples Preparation}

The spices were obtained from markets in Accra. Those not in powdered form were pulverized. A total of 22 different spices were labelled; NS (6) for natural spices (the fiber, roots, leaves) and IPS (16) for industry produced spices (packaged and imported). All were put in plastic bags and stored at $2^{\circ} \mathrm{C}$ until ready to be used. 
A $2 \mathrm{~g}$ portion of each of the samples was weighed into a clean $50 \mathrm{~mL}$ Falcon tube and extracted serially with three 10 $\mathrm{mL}$, of water each time voltexing for 5 minutes and incubating at room temperature for 30 minutes (cold extract). The extraction was repeated with a variation in the incubation temperature to $30^{\circ} \mathrm{C}$. The extracted samples were subsequently stored at $2^{\circ} \mathrm{C}$ until used. The following tables (1 and 2) present the nomenclature of the spices used in this study.

Table 1. Names of the natural spices with their labels

\begin{tabular}{cccc}
\hline ID & Scientific name & English name & $\begin{array}{c}\text { Local names } \\
\text { (Ghana) }\end{array}$ \\
\hline *NS1 & Syzygium aromaticum & Cloves & Pepere \\
NS2 & Piper guineese & Ashanti pepper & Esurowisa \\
NS3 & Rosmarinus officinalis & Rosemary & Rosemary \\
NS4 & & Aniseed & Nkitikiti \\
NS5 & Aframomum melegueta & Melegueta pepper & Efomwisa \\
NS6 & Myristica fragrans & Nutmeg & Nutmeg \\
\hline
\end{tabular}

$* \mathrm{NS}=$ natural spices

Table 2. Names of the industry produced spices with their labels

\begin{tabular}{ll}
\hline ID & Names \\
IPS1 & Curry A \\
IPS2 & Curry B \\
IPS3 & Fish Seasoning powder \\
IPS4 & Chicken seasoning powder \\
IPS5 & Fish seasoning \\
IPS6 & Chilli \& Tomato \\
IPS7 & Mixed ginger, onion. garlic \\
IPS8 & Shrimp \\
IPS9 & Mixpy \\
IPS10 & Cube shrimp \\
IPS11 & Cube shrimp \\
IPS12 & Fish flavour \\
IPS13 & Chicken flavour \\
IPS14 & Goat meat flavour \\
IPS15 & Fried rice seasoning \\
IPS16 & Jollof rice seasoning \\
\hline & \\
\hline
\end{tabular}

*IPS $=$ industry produced spices

\subsection{Analysis of Phenolic Content}

The polyphenolic contents were determined by a modified Folin-Ciocalteu method using Gallic acid as standard [7]. A $50 \mu \mathrm{L}$ portion of each of the extracted sample was mixed with $3 \mathrm{~mL}$ of distilled water $\left(\mathrm{dH}_{2} \mathrm{O}\right)$ and $250 \mu \mathrm{L}$ of a 1 in 10 diluted Folin-Ciocalteu phenol Reagent. The mixtures were allowed to stand for 5 minutes, after which $750 \mu \mathrm{L}$ of $20 \%$ $\mathrm{Na}_{2} \mathrm{CO}_{3}$ was added. This was thoroughly mixed and incubated for 30 minutes at room temperature in a dark place. Absorbance was measured at $760 \mathrm{~nm}$ using a UV-VIS Spectrophotometer (Shimadzu, 1201, Japan). All determinations were performed in triplicate.

Calibration curves were prepared using serial dilutions of $1 \mathrm{mg} / \mathrm{mL}$ Gallic acid dissolved in water to the following concentrations, $0.2 \mathrm{mg} / \mathrm{mL}, 0.4 \mathrm{mg} / \mathrm{mL}, 0.6 \mathrm{mg} / \mathrm{mL}, 0.8$ $\mathrm{mg} / \mathrm{mL}$ and $1 \mathrm{mg} / \mathrm{mL}$ each time the samples were analysed. A regression equation for the two curves used were determined to be; $y=0.196 x+0.117$ with a regression factor of $\mathrm{r}^{2}=0.92$, and $\mathrm{y}=0.169 \mathrm{x}+0.094$ with a regression factor of $r^{2}=0.95$ for when the cold and $30^{\circ} \mathrm{C}$ extract were analysed respectively.

Total phenolic content in each extract was determined from the respective curves and expressed as milligram Gallic equivalent per gram of spices sample (mg GAE/g).

\subsection{Analysis of Flavonoid Content}

The Aluminium Chloride colorimetric assay method [8] was employed to evaluate total flavonoid content in the spices using Quercetin as standard. An aliquot of $500 \mu \mathrm{L}$ extract was mixed with the following, $1500 \mu \mathrm{L}$ of $99.9 \%$ ethanol, $100 \mu \mathrm{L}$ of $1 \mathrm{M}$ potassium acetate, $100 \mu \mathrm{L}$ of $10 \%$ Aluminium Chloride and $3000 \mu \mathrm{L}$ of distilled water. The resulting mixtures were incubated for 30 minutes at room temperature and corresponding absorbance measured at $415 \mathrm{~nm}$. All determinations were carried out in triplicates.

Standard calibration curves were constructed using Quercetin standard solutions of $12.5 \mu \mathrm{g} / \mathrm{mL}, 25 \mu \mathrm{g} / \mathrm{mL}, 50$ $\mu \mathrm{g} / \mathrm{mL}, 75 \mu \mathrm{g} / \mathrm{mL}$ and $100 \mu \mathrm{g} / \mathrm{mL}$ each time the samples were analysed. $500 \mu \mathrm{L}$ of each standard was treated in the same manner as the samples above. The linear regression equation $\mathrm{y}=0.124 \mathrm{x}-0.014$ with a regression factor $\mathrm{r}^{2}=0.99$, and $\mathrm{y}=0.141 \mathrm{x}-0.053$ with $\mathrm{r}^{2}=0.98$ were generated when the cold and $30^{\circ} \mathrm{C}$ extract was analysed.

Flavonoid content of each extract were determined from the curve and expressed as microgram Quercetin equivalent per gram spice sample ( $\mu \mathrm{g} Q \mathrm{Q} / \mathrm{g})$.

Table 3. A Heat-map representation of the Ingredients of IPS

\begin{tabular}{|c|c|c|c|c|c|c|c|c|c|c|c|c|c|c|}
\hline INGREDIENTS & $\overline{0}$ & Ñ & $\begin{array}{l}\mathscr{D} \\
\hat{\theta}\end{array}$ & $\begin{array}{l}\frac{n}{\infty} \\
\mathscr{G}\end{array}$ & $\begin{array}{l}\overline{\mathscr{Q}} \\
\text { 气 }\end{array}$ & $\hat{\mathscr{n}}$ & $\begin{array}{l}\hat{\mathscr{Q}} \\
\hat{=}\end{array}$ & 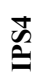 & $\begin{array}{l}\text { ㅁ } \\
\text { 苟 }\end{array}$ & ஜ̊ & $\frac{n}{\mathscr{\Omega}}$ & 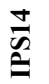 & ஜ̂. & $\stackrel{\infty}{\mathscr{\Omega}}$ \\
\hline Sugar & & & & & & & & & & & & & & \\
\hline Salt & & & & & & & & & & & & & & \\
\hline Starch & & & & & & & & & & & & & & \\
\hline Garlic & & & & & & & & & & & & & & \\
\hline Flavour Enhancement (E621, E631,) & & & & & & & & & & & & & & \\
\hline
\end{tabular}




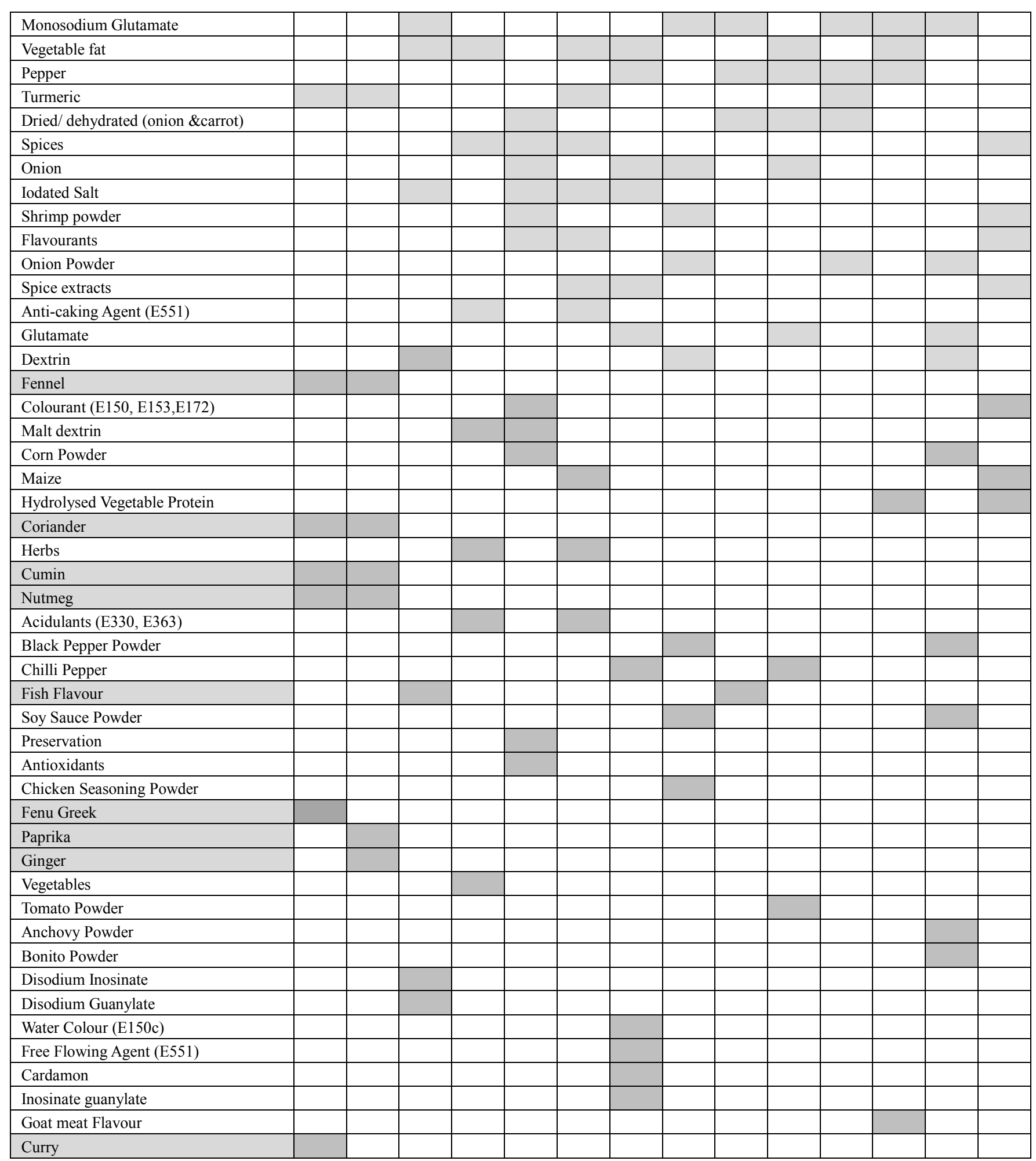

Table 4. Concentrations of Phenolic and Flavonoids extracted from the IPS

\begin{tabular}{|c|c|c|c|c|c|c|c|c|c|c|c|c|c|c|}
\hline Extracted substance & \multicolumn{14}{|c|}{ Concentrations $\left\{\right.$ phenolics-x $10^{-2}$ ng GAE/g\} \{flavonoids- $\left.\times 10^{2} \mu \mathrm{g} Q \mathrm{Q} / \mathrm{g}\right\}$} \\
\hline INGREDIENTS & $\bar{n}$ & $\tilde{\omega}$ & $\hat{\varrho}$ & $\frac{n}{\hat{n}}$ & $\overline{\bar{a}}$ & $\hat{n}$ & $\hat{\hat{a}}$ & $\stackrel{H}{\Leftrightarrow}$ & $\frac{\widetilde{a}}{\tilde{n}}$ & 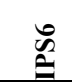 & $\frac{a}{a}$ & $\begin{array}{l}\frac{\Delta}{n} \\
\hat{=}\end{array}$ & $\tilde{\omega}$ & $\begin{array}{c}\infty \\
\Leftrightarrow \\
\Leftrightarrow\end{array}$ \\
\hline Phenolic ( cold) & 1.50 & 1.25 & 0.79 & 0.46 & 0.54 & 0.50 & 0.50 & 0.07 & 0.67 & 0.35 & 0.20 & 0.00 & 0.00 & 0.00 \\
\hline Phenolic ( warm) & 4.47 & 5.61 & 0.34 & 0.09 & 0.27 & 0.26 & 0.33 & 0.27 & 0.01 & 0.08 & 0.32 & 0.00 & 0.0 & 0.0 \\
\hline Flavonoid (cold) & 81.57 & 98.62 & 18.26 & 14.99 & 13.91 & 16.25 & 10.70 & 5.39 & 12.68 & 6.74 & 29.34 & 0.0 & 0.0 & 0.0 \\
\hline Flavonoid (warm) & 72.17 & 61.06 & 17.43 & 16.19 & 13.05 & 10.42 & 7.28 & 7.11 & 6.32 & 6.27 & 6.03 & 0.0 & 0.0 & 0.0 \\
\hline
\end{tabular}




\section{Results}

\subsection{Phenolic Concentration}

With respect to the phenolic content of the spices studied, two clear categories were observed; one with seven spices (5 of which were natural spices (NS) and 2 IPS that contained relative high amounts, ranging between $12 \mathrm{ng} \mathrm{GAE} / \mathrm{g}$ and $370 \mathrm{ng}$ GAE/g (Figure 1). The second category included eleven (11) IPS that contained between $0.1 \mathrm{ng} \mathrm{GAE} / \mathrm{g}$ and $7.9 \mathrm{ng} \mathrm{GAE} / \mathrm{g}$ of phenolics (Figure 2).

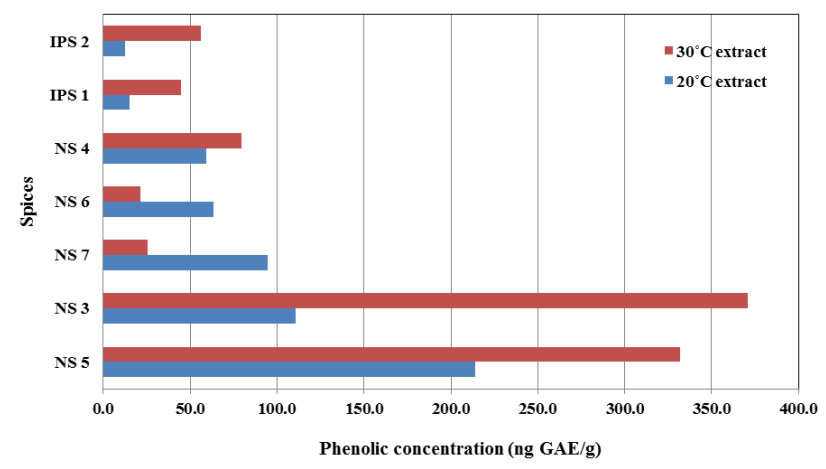

Figure 1. Cold and warm extracts of spices with higher phenolic concentration, reported as ng GAE/g. IPS= industry produced spices, NS= Natural spices

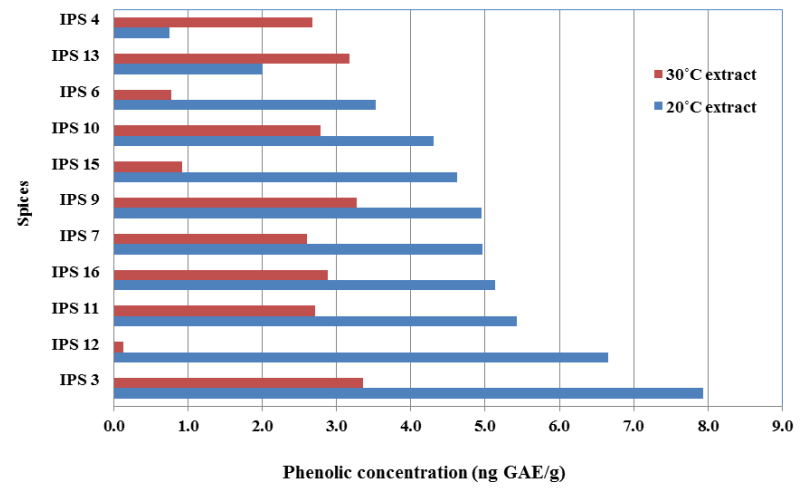

Figure 2. Cold and warm extracts of spices with lower phenolic concentration, reported as $n g$ GAE/g.. IPS= industry produced spices, NS=Natural spices

Considering the relative amounts extracted at the different temperatures, it was observed that the spices that recorded higher phenolic contents (Figure 1) had relatively higher amounts of phenolic extracted by the warm extraction, except for two spices (NS 6 and NS 7). On the average warm extractions yielded $39.5 \%$ more phenolic content than the cold extraction. However, there was a positive correlation between the amounts obtained by both methods; a correlation coefficient of 0.738 was observed. The converse was true for the spices that recorded lower amounts of phenolic; except for IPS 4 and IPS 13, all the others recorded higher amounts of phenolic with cold extraction compared to warm extraction (Figure 2) with an average difference of $56.4 \%$. A correlation was observed in this case with coefficient of -0.092 .

\subsection{Flavonoid Concentration}

The spices studies were categorized into two groups based on whether they recorded flavonoid contents of less than $0.50 \mu \mathrm{g} \mathrm{QE} / \mathrm{g}$ (lower group) with both extraction methods or greater (higher group) with at least one of the extraction methods. All the local spices were in the higher group in addition to two of the IPS; while the lower consisted of only IPS. The flavonoids extracted from the higher group, by cold extraction, ranged between $0.3 \mu \mathrm{g} \mathrm{QE} / \mathrm{g}$ and 3.7 $\mu \mathrm{g} \mathrm{QE} / \mathrm{g}$ while that by warm extraction ranged between $0.2 \mu \mathrm{g} \mathrm{QE} / \mathrm{g}$ and 3.5 $\mu \mathrm{g} \mathrm{QE} / \mathrm{g}$ (Figure 3). The ranges for the lower group were between $0.05 \mu \mathrm{g} \mathrm{QE} / \mathrm{g}$ and $0.29 \mu \mathrm{g} / \mathrm{g}$ for cold extraction, and $0.07 \mu \mathrm{g} \mathrm{QE} / \mathrm{g}$ and $0.17 \mu \mathrm{g} / \mathrm{g}$ for warm extraction (Figure 4).

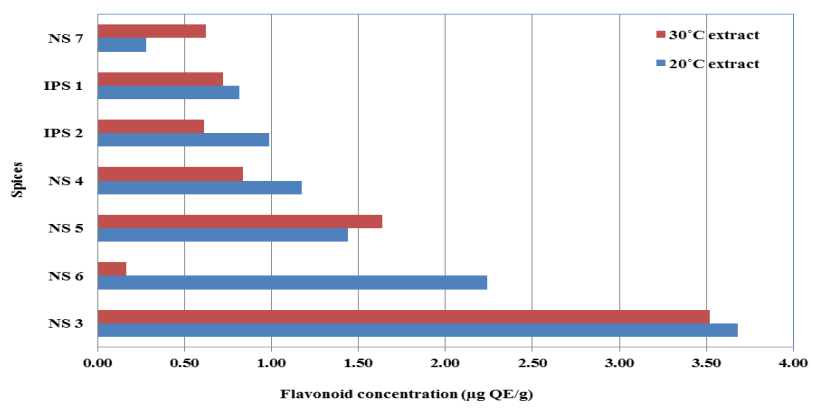

Figure 3. Cold and warm extracts of spices with higher flavonoid concentration, reported as $\mu \mathrm{g} Q E / g$. IPS= industry produced spices, $N S=$ Natural spices

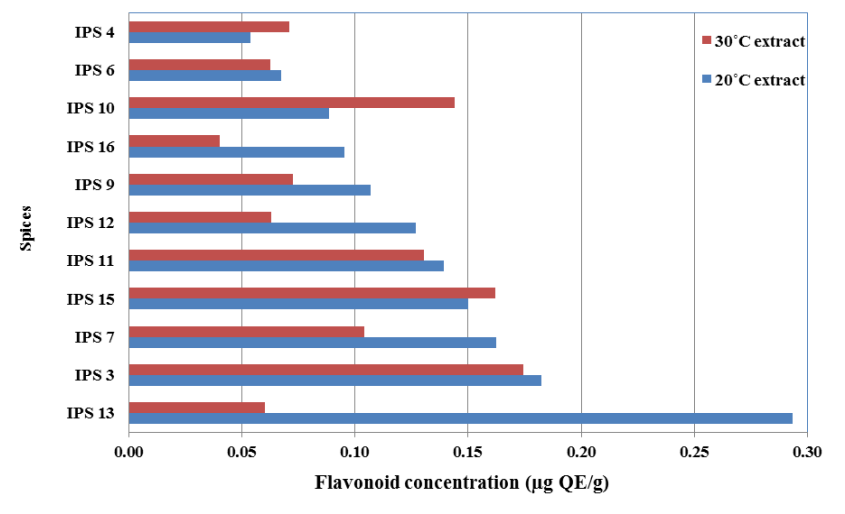

Figure 4. Cold and warm extracts of spices with lower flavonoid concentration, reported as $\mu \mathrm{g} Q E / g$. IPS= industry produced spices, $N S=$ Natural spices

\subsection{Components of IPS and Amounts of Phenolic and Flavonoids}

A closer look at the ingredients of the IPS with respect to their phenolic and flavonoid concentrations showed that for the IPS that recorded more than $0.010 \mathrm{ng}$ GAE/g phenolic, 
by both warm and cold extractions, the following components; Curry, Fenu Greek, Paprika, Ginger, Cumin, Nutmeg, Coriander and Fennel were present in their composition (Table 3). Regarding a similar analysis for IPS that recorded a flavonoid concentration of $0.15 \mu \mathrm{g} \mathrm{QE} / \mathrm{g}$ or higher, in both warm and cold extractions, the following components were present; Curry, Vegetables, Ginger, Paprika, Fenu Greek, Nutmeg, Cumin, Coriander, and Fennel. These components are the most likely contributing to the relatively higher phenolic and flavonoids with vegetables seemingly contributing more to the relatively higher flavonoids.

\section{Discussion}

The higher amounts of phenolic and flavonoids extracted from the NS relative to those extracted from the IPS (Figures 1-4) is to be expected since the ingredients of the IPS although included some natural spices, also included a lot of other substances, such as Sugar, Salt, Starch, Monosodium Glutamate, and hydrolysed vegetable protein among others (Table 3) that are not expected to contribute its content of phenolic and flavonoids. However, it was interesting to find that the NS with the highest content of phenolic recorded 40 times the phenolic content of the IPS; and for flavonoids it was 10 times. It is also possible that depending on how the IPSs were processed, they may have lost some amounts of their phenolic and flavonoids. The only two IPSs that recorded high amounts of both phenolic and flavonoid; IPS1 and IPS2, were the only IPSs that contained some particular ingredients (Table 3). These ingredients, which were curry, ginger, paprika, fenu greek, nutmeg, cumin, coriander and fennel are most likely contributing to the relatively higher phenolic and flavonoids of these IPS. Also, vegetables seemingly contributed to the relatively higher flavonoids and not the relatively higher phenolic since it was the only ingredients that was in the IPS 3 and IPS4 that also recorded slightly high flavonoid but not phenolic (Table 4).

Mantas et al., 2010 in their studies on some plant spices, not processed, reported the highest content of phenolic compounds to be $1637.1 \pm 0.7 \mathrm{mg}$ of Gallic acid equivalents per $100 \mathrm{~g}$ of dry plant material correspondingly and the lowest content to be $233.1 \pm 0.3 \mathrm{mg}$ GAE/100 g. Also, Settharaksa et al., 2012 in their studies, found that the extracts from hot curry, presented flavonoid and phenolic contents in the range of 0.04-11.18 mg Catechin equivalent (CE)/100 g sample and 0.68-134.91 mg Gallic acid equivalent (GAE)/100g sample respectively.

Comparing the yields of the two temperatures of extraction, generally for the spices that recorded a high phenolic content (which were mostly the NS) the extractions at warm temperature yielded averagely 39.5\% more phenolic relative to extraction at cold temperature. However, a high yield by the warm extraction was associated with a high yield by cold extraction, $74.0 \%$ of the time.

On the other hand, for the spices that had a low phenolic content (which were mostly the IPS) an average of 56.4\% more phenolic were extracted at the cold temperature relative to the warm temperature and interestingly, a higher yield by cold extraction was associated with a lower yield by warm extraction but only $9.2 \%$ of the time. However, it is worth noting that the two IPS that recorded higher phenolic (IPS1 and IPS2) did not follow this trend; they showed the trend for the NS where warm extraction yielded more phenolic. These differences therefore suggests that for spices that have high phenolic contents, warm extraction is most likely to result in higher yields while for those that may have lower contents, a cold extraction may have a higher yield. Although this study did look at the type/nature of the phenolic extracted at both temperatures, it is also likely that the nature of the extracted phenolic if different may influence the yields at the different temperatures.

The observations for the flavonoid were the reverse, for both types of spices studied and for both high and low yields of flavonoids, higher amounts of flavonoids were extracted by the cold method by an average of $34.5 \%$ (Figures 3 and 4 ). These were 5 of the 7 high-yield group spices and 8 of the 11 low-yield group of spices, which represented $72 \%$ of the spices. On the other hand, for $28 \%$ of the spices that yielded higher amounts of flavonoid by warm extraction, an average difference of $27.4 \%$ was recorded. Similarly, although not studied, the difference may possibly partly be due to the nature of the flavonoids in these spices.

\section{Conclusion}

The present investigations revealed that generally, natural spices will potentially contribute extremely more phenolic and flavonoid than industry produced spices if about the same amounts are used in preparing food. Further, spices have many phytochemicals which are a potential source of natural antioxidant, e.g., phenolic and flavonoids. However, the selection of industry produced spices based on the presence of some ingredients may result in slightly higher phenolic and flavonoid contribution to foods.

Also, a difference in temperature of $10^{\circ} \mathrm{C}$ between a warm and a cold extraction methods may influence the effectiveness of extracting phenolic and flavonoid from natural and processed spices similar to the once in this study.

\section{References}

[1] Ogunka-Nnoka and Mepba, "Proximate Composition and Antinutrient Contents of Some Common Spices in Nigeria" The Open Food Science Journal, 2008, 2: 62-67.

[2] Gupta, C., Garg, A. P and Uniyal R. C., "Antimicrobial and Phytochemical studies of Amchur (Dried Pulp of Unripe Mangifera Indica) extract on Some Food Borne Bacteria". The Internet Journal of Tropical Medicine, 2009,5 (2):1540-2681.

[3] Onianwa, P. C., Adetola, I. G., Iwegbue, C. M. A., Ojo, M. F. and Zaichik, V., "Trace heavy metals composition of some Nigerian beverages and food drinks". Food Chem., 1999, 66:275 - 279 . 
[4] Lampe, J. W., "Spicing up a vegetarian diet: chemopre ventive effects of phytochemicals". American Journal of Clinical Nutrition, 2003, 78(3):579-583.

[5] Halvorsen, B. L., Holte, K. and Myhrstad, M. C. W., "A systematic screening of total antioxidants in dietary plants". J Nutr., 2002,132: 461-71.

[6] Okwu, D. E., "Phytochemicals and vitamins content of indigenous spices of South-Eastern Nigeri"a. J. Sustain. Agric. Environ., 2004, 6:30-34.

[7] Singleton V.L., R. Orthofer, R. M., "Lamuela-Raventós, P. Lester. Methods in Enzymology", Academic Press, 1999, 152-178.
[8] Zhishen J., Mengcheng T., Jianming W., "The determination of flavonoid content in mulberry and their scavenging effects on superoxide radicals" Food Chem. 1999,64:555-559

[9] Mantas Stankevičius, Ieva Akuneca, Ida Jãkobsone, Audrius Maruška, "Analysis of phenolic compounds and radical scavenging activities of spice plants extracts" 2010,44:85-91

[10] Settharaksa S, Jongjareonrak A, Hmadhlu P, Chansuwan, W. ,Siripongvutikorn S., "Flavonoid, phenolic contents and antioxidant properties of Thai hot curry paste extract and its ingredients as affected of $\mathrm{pH}$, solvent types and high temperature" International Food Research Journal 2012, 19(4): 1581-1587 